\title{
0 trabalho do menor de idade no meio rural e o princípio da proteção integral
}

\author{
José Antonio Miguel ${ }^{1}$ \\ Vilma Aparecida do Amaral ${ }^{2}$
}

\begin{abstract}
Resumo
o Trabalho do menor de idade é tema de grandes discussões e ainda é visto como um problema por muitos países no mundo. 0 Brasil é um país que tem grande parte de sua economia advinda do meio agrícola. Essa realidade é encontrada mais facilmente em pequenos municípios, cuja economia depende desse tipo de atividade. Em vista disso e da precarização dos direitos dos trabalhadores rurais, estes se vêem obrigados a complementar a renda de suas famílias com o trabalho dos seus filhos menores de idade. Assim, diante do Princípio da Proteção Integral posto no art. 227 da Constituição Federal, além de toda legislação infraconstitucional, como a CLT e o ECA, e considerando as pesquisas apontadas e realizadas no trabalho, procurou-se entender a realidade desses menores e a conseqüente aplicação da legislação nesse tipo de relação de trabalho, tanto nas relações de emprego no meio rural, ou mesmo na condição de aprendiz. Contudo, em vista da impossibilidade econômica e da realidade sócio-cultural do país, existe grande dificuldade na aplicação de toda legislação pertinente, bem como, o Estado não pratica políticas públicas voltadas à extinção desse tipo de exploração. Desse modo, o trabalho executado pelos menores de idade no meio rural é o trabalho mais realizado por esses cidadãos, em desrespeito ao Princípio da Proteção Integral, sendo assim, meio para o desrespeito à condição de pessoa em desenvolvimento.
\end{abstract}

Palavras-Chave: Trabalho; Menor de idade; Trabalho rural; Princípio da Proteção Integral; Constituição Federal; CLT; ECA.

\section{Introdução}

0 Trabalho do menor de idade sempre foi tema de muitas discussões. A realidade brasileira aponta para um grande número de menores de idade trabalhadores no campo, que, na maioria dos casos, fazem parte de família de trabalhadores rurais, que têm grande parte dos seus direitos defasados, ou são remunerados por produção (bóias-frias), situação que os obriga a ajudar na complementação da renda familiar.

A vigente Constituição Federal positivou o princípio da proteção integral, regulamentado pelo ECA, pela CLT e por legislações esparsas. Contudo, as normas referentes

\footnotetext{
${ }^{1}$ Bacharel em Direito pela UEL; Advogado; Aluno da Especialização em Direito na Fundação Escola doM inistério Público do Paraná.

${ }^{2}$ Mestre em Direito pela UEL; Professora da UEL.
} 
ao trabalho do menor de idade, mesmo dotadas de caráter cogente, não são efetivadas, em grande maioria por falta de políticas públicas.

Em vista disso, o trabalho trata dos direitos que deveriam ser cumpridos, bem como em que condições o menor de idade poderá trabalhar, seja como empregado ou como aprendiz, e até mesmo na agricultura familiar.

\section{A proteção do trabalho do menor de idade no Brasil}

A proteção ao trabalho do menor de idade no Brasil é iniciada pelo Decreto n. 1.313 de 17.01.1890, que estabelecia somente normas gerais. Em seguida, encontra-se o Decreto 16.300 de 1923, que vedou o trabalho aos menores de 18 (dezoito) anos por mais de 6 (seis) horas por dia.

0 Código de Menores foi aprovado em 12.10.1927, e proibia o trabalho aos menores de 12 (doze) anos, e o trabalho noturno aos menores de 18 (dezoito).

A Constituição de 1934 em seu artigo 121, d, proibiu o trabalho aos menores de 14 (quatorze) anos. 0 mesmo foi disposto pela Carta Maior de 1937 em seu art. 137, k, e pela Constituição de 1946, no inciso X do art. 157.

Somente a Constituição de 1967, no art. 165, X, mudou o patamar anterior para 12 (doze) anos, prevalecendo até a Constituição de 1988.

Em princípio, a idade estabelecida pela vigente Constituição era de 14 (quatorze) anos. Contudo, a redação do art. 7ํ, XXXIII foi alterada pela Emenda Constitucional n. 20 de 1998, estabelecendo que é defeso o trabalho noturno, perigoso ou insalubre aos menores de 18 (dezoito) anos e de qualquer trabalho a menores de 16 (dezesseis), salvo na condição de aprendiz a partir dos 14 (quatorze).

Contudo, a Norma Soberana preceitua no art. 227, §3으, inciso I que

0 direito a proteção especial abrangerá os seguintes aspectos: I - idade mínima de quatorze anos para admissão ao trabalho, observado o disposto no art. 7ํ, XXXIII.

Pode-se observar que a própria Constituição abre caminhos para interpretações distintas. No art. 70, XXXIII, a idade mínima para o trabalho é de 16 (dezesseis) anos, sendo que na condição de aprendiz somente a partir dos 14 , sendo vedado qualquer trabalho 
noturno, perigoso ou insalubre. Já 0 inciso I do $\S 30$ do art. 227 estabelece como idade mínima quatorze anos (TEIXEIRA, 2003).

Outro erro com relação à matéria é encontrado no art. 60 da Lei 8.069 de 13.07.1990 (Estatuto da Criança e do Adolescente - ECA), que preceitua que "é proibido qualquer trabalho a menores de 14 (quatorze) anos de idade, salvo na condição de aprendiz". Uma interpretação gramatical do referido artigo leva a crer que a idade mínima para o trabalho é de quatorze anos, e que aos menores dessa idade é possível exercer algum tipo de trabalho, desde que na condição de aprendiz.

Contudo, a matéria é regulamentada, segundo preceitua 0 art. 61 do ECA, por legislação especial, ou seja, a Consolidação das Leis do Trabalho (CLT), mais especificamente na Lei 10.097, de 19.12.2000, que estabelece que 0 art. 403 da CLT tenha a seguinte redação: "É proibido qualquer trabalho a menores de dezesseis anos de idade, salvo na condição de aprendiz, a partir dos quatorze anos".

Portanto, todo trabalho é proibido aos menores de dezesseis anos, exceto quando na condição de aprendiz, a partir dos quatorze, conforme estabelecido pela legislação acima citada.

A proteção ao trabalho ainda está nos incisos I, II e III do § 30 do art. 227 da Constituição Federal. Além da idade mínima para o trabalho, os referidos incisos garantem os direitos previdenciários e trabalhistas, e 0 acesso do trabalhador adolescente à escola, 0 que será tratado em um ponto específico.

\section{0 princípio da proteção integral}

Ensina Miguel Reale (2002, p. 303), que sendo o Direito uma ciência, uma forma de conhecimento científico e filosófico, há nele princípios, ou seja, enunciados lógicos admitidos como condição ou base de validade das demais asserções que compõem dado campo do saber.

Luis de Pinho Pedreira da Silva (1999, p. 25) ensina que na Ciência Jurídica existem duas espécies de princípios: os Princípios Gerais do Direito e os princípios gerais de cada disciplina jurídica. A essa regra não foge quando se trata de Direito da Criança e do Adolescente. 
O Princípio da Proteção Integral está positivado no art. 227, § 30 e seus incisos da Constituição Federal, e no art. 10 do Estatuto da Criança e do Adolescente.

0 motivo dessa proteção integral dada pela legislação está exposto na referida lei, quando 0 art. 3을 estabelece que

A criança e 0 adolescente gozam de todos os direitos fundamentais inerentes à pessoa humana, sem prejuízo da proteção integral de que trata esta Lei, assegurando-se-Ihes, por lei ou por outros meios, todas as oportunidades e facilidades, a fim de lhes facultar o desenvolvimento físico, mental, moral, espiritual e social, em condições de liberdade e igualdade. (grifo nosso)

A finalidade do princípio positivado da Proteção Integral é proporcionar meios que façam a criança e 0 adolescente se desenvolver nos aspectos físico, mental, moral, espiritual e social. O legislador quis dar uma igualdade material às crianças e aos adolescentes, tratando esses desiguais de maneira desigual, para que a condição de igualdade possa ser alcançada na obtenção dos seus direitos. Isso acontece pela preocupação do Estado em não comprometer o desenvolvimento biológico, psicológico, intelectual e moral desses cidadãos.

A Proteção Integral não é a proteção apenas positivada em lei, ou seja, a sociedade não pode se furtar de realizar qualquer tipo de ação que vise à proteção desses menores de idade. Essa proteção enfatizada no Estatuto é sinônimo de dar amparo completo, sob todos os aspectos que contribuem para o desenvolvimento da criança e do adolescente, com vistas a assegurar todos os direitos fundamentais proporcionando-Ihes a efetivação da dignidade humana (SEGUNDO, 2003).

\section{Instrumentos previstos no estatuto da criança e do adolescente para efetivação do princípio da proteção integral}

A Constituição de 1988 introduziu no Estado Brasileiro uma nova forma de federalismo, até então desconhecida. Na consolidação da nova ordem democrática, a descentralização e a participação popular passam a ter maior importância. E tamanha é a importância disso, que logo no primeiro artigo a Constituição garante que todo poder emana do povo, que o exerce por meio de representantes eleitos ou diretamente, nos termos desta Constituição (ROCHA; PEREIRA, 2007). A Constituição prevê ainda a criação de conselhos, órgãos deliberativos ou consultivos, compostos por representantes da sociedade civil, e que 
tem por objetivo a efetivação dos princípios constitucionais e de políticas públicas sobre determinados temas.

Por se tratar de direito difuso, o ECA se utiliza desses instrumentos de efetivação, quando nos artigos 88, II, prevê a criação do Conselho da Criança e do Adolescente, nos âmbitos estadual, federal e municipal, além do art. 131 prever a criação do Conselho Tutelar, em cada município. Não obstante, o Estatuto ainda prevê a possibilidade de criação de varas especializadas da infância e juventude; a intervenção obrigatória do Ministério Público nos procedimentos em que algum menor de idade for envolvido; e políticas públicas voltadas à criança e ao adolescente.

Dos instrumentos citados, o que merece atenção no momento é o Conselho Tutelar. Estes órgãos devem ser criados por Lei Municipal que disporá sobre local, dia e horário de funcionamento, bem como eventual remuneração de seus membros (art. 134). Esses membros são eleitos diretamente pela comunidade, para mandato de três anos. 0 Conselho goza ainda de autonomia, além de serem permanentes e independentes, e não jurisdicionais.

Sua autonomia está no fato de não necessitar de ordem judicial para aplicação de medidas protetivas (arts. 98 a 102 do ECA). Já sua independência é relativa, pois está submetido à fiscalização do Conselho M unicipal da Criança e do Adolescente, do Ministério Público, da autoridade judiciária, bem como da sociedade.

0 artigo 136 do ECA ${ }^{3}$ elenca as atribuições do Conselho, não sendo essas atribuições exaustivas somente ao que estabelece a lei, ou seja, o Conselho não deve se restringir somente ao que está exposto no artigo mencionado, pois como dito, o ECA trata de direito

\footnotetext{
${ }^{3}$ Art. 136. São atribuições do Conselho Tutelar: I - atender as crianças e adolescentes nas hipóteses previstas nos arts. 98 e 105, aplicando as medidas previstas no art. 101, I a VII ;II - atender e aconselhar os pais ou responsável, aplicando as medidas previstas no art. 129, I a VII; III - promover a execução de suas decisões, podendo para tanto: a) requisitar serviços públicos nas áreas de saúde, educação, serviço social, previdência, trabalho e segurança; b) representar junto à autoridade judiciária nos casos de descumprimento injustificado de suas deliberaçõ̃es; IV - encaminhar ao Ministério Público notícia de fato que constitua infração administrativa ou penal contra os direitos da criança ou adolescente; $V$ - encaminhar à autoridade judiciária os casos de sua competência; VI - providenciar a medida estabelecida pela autoridade judiciária, dentre as previstas no art. 101, de I a VI, para o adolescente autor de ato infracional; VII - expedir notificações; VIII requisitar certidões de nascimento e de óbito de criança ou adolescente quando necessário; IX - assessorar o Poder Executivo local na elaboração da proposta orçamentária para planos e programas de atendimento dos direitos da criança e do adolescente; $X$ - representar, em nome da pessoa e da família, contra a violação dos direitos previstos no art. 220, § 3o, inciso II, da Constituição Federal;XI - representar ao Ministério Público, para efeito das ações de perda ou suspensão do pátrio poder. Ibid.
} 
difuso, assim sendo, todas as medidas cabíveis para a proteção da criança e do adolescente devem ser adotadas por todos os segmentos sociais que visem a efetivação dessa proteção.

\title{
Legislação sobre o menor de idade empregado no meio rural
}

A regulamentação da lei 5.889 de 1973 quanto ao menor de idade empregado

A lei que rege as relações de Trabalho Rural no Brasil é a Lei 5.889 de 08 de junho de 1973. Essa lei conceitua o que é empregado e empregador rural. Segundo o seu artigo 2º,

\begin{abstract}
Empregado rural é toda pessoa física que, em propriedade rural ou prédio rústico, presta serviços de natureza não eventual a empregador rural, sob dependência deste e mediante salário.

No artigo seguinte, a referida Lei estabelece que

Considera-se empregador rural, para os efeitos desta Lei, a pessoa física ou jurídica, proprietário ou não, que explore atividade agroeconômica, em caráter permanente ou temporário, diretamente ou através de prepostos e com auxílio de empregados. $\S 1$ - Inclui-se na atividade econômica referida no caput deste artigo a exploração industrial em estabelecimento agrário não compreendido na Consolidação das Leis do Trabalho.

Contudo, nos dizeres de Jorge Luiz Souto Maior (GIORDANI, 2005),

a Constituição de 1988, art. 70, caput, finalmente, tratou de forma igualitária, urbanos e rurais, quanto aos direitos que assegurou aos trabalhadores. Com isso, os direitos conferidos aos trabalhadores rurais são os mesmos que se confere, atualmente, aos trabalhadores urbanos, inclusive quanto à proteção previdenciária. Apenas pra atender às peculiaridades do trabalho no campo, alguns direitos têm regulação específica na Lei n. 5.889/73 e na própria Constituição Federal.
\end{abstract}

Com relação ao menor de idade a referida lei pouco regulamenta. No seu artigo 80 veda aos menores de 18 (dezoito) anos o trabalho noturno, em conformidade com o disposto no inciso XXXIII do art. 70 da CF. Depois, estabelece no parágrafo único do artigo 10 ㅇ que contra o menor não corre prescrição.

Outro aspecto com relação ao menor de idade e tratado pela Lei do Trabalho Rural é com relação ao salário desses trabalhadores. Estabelece 0 art. 11 que os maiores de 16 anos que trabalhem no meio rural é assegurado o salário mínimo igual ao adulto trabalhador. Contudo, o problema está no seu parágrafo único, que reza que "ao empregado menor de 16 (dezesseis) anos é assegurado salário mínimo fixado em valor correspondente à metade do salário mínimo estabelecido para o adulto." 
A referida regra era na realidade uma brecha para empregadores que queiram aproveitar de mão de obra barata. Como será exposto, a maioria absoluta desses jovens trabalham nas mesmas condições e com a mesma carga horária dos adultos, e mesmo assim o legislador da época não levou isso em consideração, dando respaldo e proteção legal a uma condição de desigualdade econômica entre os menores de 16 (dezesseis) anos e os demais trabalhadores.

Contudo, como leciona Ricardo Tadeu Marques da Fonseca (GIORDANI, 2005),

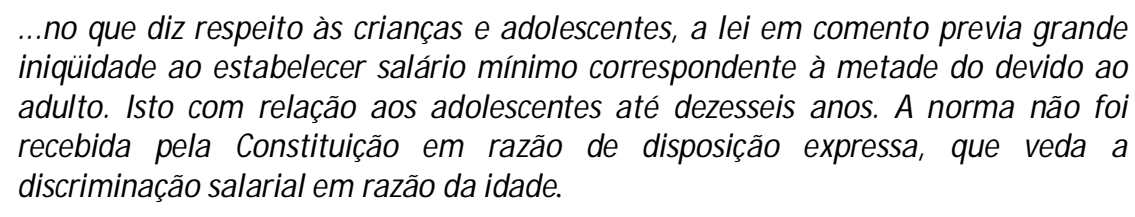

Portanto, com o advento da Constituição de 1988, mais especificamente no inciso XXX do art. 70, qualquer diferença salarial que seja em decorrência de sexo, idade, cor ou estado civil é proibida, dando, neste caso, aos menores de idade, efetividade ao princípio da igualdade.

\section{A Constituição Federal e o menor de idade empregado}

A Constituição Federal estabelece que idade mínima para o trabalho do menor de idade no Brasil é de 16 anos $^{4}$. A partir dessa idade, o menor de idade empregado deve ter todos os direitos advindos dessa relação.

Como dito alhures ${ }^{5}$, qualquer discriminação salarial por motivo de idade do trabalhador, conforme estabelece 0 inciso XXX do art. $7^{0}$ da Carta Magna, é proibida, devendo, portanto, o menor de idade empregado receber o salário mínimo vigente, ou até mesmo, salário maior, dependendo de sua função.

A Constituição de 1988 destinou um capítulo para tratar da criança, do adolescente e do idoso (Titulo VIII, Capitulo VII). Mais especificamente, foi no art. 227, § 3으, incisos I, II e III que a Lei Maior tratou da questão do trabalho do menor de idade.

Nos dizeres de José Afonso da Silva (2004, p. 316),

\footnotetext{
${ }^{4}$ Vide Cap. 2. do presente trabalho.

${ }^{5}$ Vide Cap. 5.1. do presente trabalho.
} 
alguns direitos sociais, reconhecidos no art. 227, são pertinentes só à criança e ao adolescente, como 0 direito à profissionalização, à convivência familiar e comunitária e as regras especiais dos direitos previdenciários e trabalhistas (art. 227, §3이 I a III).

Como discorrido6, embora o inciso I do artigo 227, §3ㅇe estabeleça a idade mínima de 14 (quatorze) anos para admissão ao trabalho, o correto é o que dispõe o art. 70 , XXXIII e 0 art. 403 da CLT, que estabelece a idade de 16 (dezesseis) anos para admissão no trabalho.

0 inciso II do § 3ㅇ do art. 227 garante os direitos previdenciários e trabalhistas aos menores de idade empregados. Saliente-se que são todos os direitos advindos de uma relação de trabalho que devem ser garantidos ao menor de idade trabalhador, inclusive os previdenciários. Contudo, a proibição do trabalho noturno, perigoso ou insalubre não veda que caso haja descumprimento desse preceito legal, o menor de idade não tenha direito aos créditos advindos desse tipo de trabalho. 0 M inistério do Trabalho e o Ministério Público do Trabalho são competentes para aplicar as devidas penalidades em caso de descumprimento.

E no inciso III, o legislador garantiu ao trabalhador adolescente o acesso à escola. Essa garantia está fundamentada no direito à educação e à profissionalização desse adolescente, direitos estes que estão positivados no caput do artigo 227.

Contudo é necessário salientar que os direitos postos nos incisos do art. 7o da Constituição Federal (salário mínimo fixado em lei, seguro-desemprego, fundo de garantia por tempo de serviço etc.), também devem ser garantidos ao menor de idade empregado, e evidentemente, também os direitos postos em legislação infraconstitucional.

A CLT e o menor de idade empregado no meio rural: o contrato de aprendizagem

Como já exposto, empregado rural é toda pessoa física que, em propriedade rural ou prédio rústico, presta serviços de natureza não eventual a empregador rural, sob dependência deste e mediante salário, como reza 0 art. 20 da Lei 5.889/73.

Dessa regra não foge o menor de idade, que para ser empregado deve reunir todas as características citadas, ou seja, ser pessoa física; prestar serviço de natureza não eventual; esse serviço deve ser em propriedade rural ou prédio rústico; estar em condição de dependência, quer dizer, subordinação; e por fim, mediante salário.

\footnotetext{
${ }^{6}$ Vide Cap. 2 do presente trabalho.
} 
A CLT preocupa-se com a proteção do menor de idade trabalhador, não somente 0 menor de idade empregado. Assim, todos os menores de idade, trabalhadores e empregados, são abrangidos pelas normas protetivas, quanto ao horário, ambiente de trabalho, entre outros aspectos previstos na CLT, e que será tratado oportunamente.

Contudo, os menores de idade que venham a ser empregados devem se submeter à regra da idade mínima de 16 (dezesseis) anos para qualquer trabalho e se for na condição de aprendiz a partir dos 14 (quatorze).

0 art. 428 da CLT estabelece que, in verbis

Contrato de aprendizagem é o contrato de trabalho especial, ajustado por escrito e por prazo determinado, em que o empregador se compromete a assegurar ao maior de 14 (quatorze) e menor de 24 (vinte e quatro) anos inscrito em programa de aprendizagem formação técnico-profissional metódica, compatível com o seu desenvolvimento físico, moral e psicológico, e o aprendiz, a executar com zelo e diligência as tarefas necessárias a essa formação.

O empregador, portanto, deverá sempre contratar o menor aprendiz por escrito e por prazo determinado. 0 menor, por sua vez, deverá estar inscrito em programa de aprendizagem, que, preferencialmente, serão ministrados pelos Serviços Nacionais de Aprendizagem, e supletivamente pelas Escolas Técnicas de Educação ou pelas entidades sem fins lucrativos, que tenham por objetivo a assistência ao adolescente e à educação profissional, desde que registradas no Conselho Municipal dos Direitos da Criança e do Adolescente (CLT, art. 430).

Conforme estabelece $0 § 2^{\circ}$ do art. 428 da CLT, 0 menor aprendiz não poderá receber salário inferior ao salário mínimo hora. Essa regra foi estabelecida pela Lei 10.097/2000 que alterou alguns artigos da CLT com relação ao trabalho do menor de idade.

0 contrato deverá ter termo certo, sendo vedado estipulação maior do que dois anos ( $\$ 3^{\circ}$ do art. 428 da CLT). Para ser válido, ainda, pressupõe a anotação na Carteira de Trabalho e Previdência Social, matrícula e freqüência do aprendiz à escola (se não concluiu o ensino fundamental), e a inscrição em programa de aprendizado.

0 art. 429 da CLT estabelece que todos os estabelecimentos de qualquer natureza são obrigados a empregar e matricular nos cursos dos Serviços Nacionais de Aprendizagem número de aprendizes equivalente a 5\% (cinco por cento), no mínimo, e 15 (quinze por cento), no máximo dos trabalhadores existentes em cada estabelecimento, cujas funções 
demandem formação profissional. Todavia, a contratação do menor aprendiz poderá ser efetivada pela empresa onde se realizará a aprendizagem ou pelas entidades sem fins lucrativos, que tenham por objetivo a assistência ao adolescente e à educação profissional, caso este que não gera vínculo de emprego com a empresa tomadora de serviços. Contudo, no caso de inadimplência da instituição de ensino, o tomador de serviço responde subsidiariamente, conforme dispõe o inciso IV da Súmula 331 do Tribunal Superior do Trabalho (TST) ${ }^{7}$.

Essas regras são aplicáveis também ao trabalho rural. Contudo, o princípio da proteção integral deve ser observado, bem como todas as regras referentes a ele, levando em consideração os limites de idade desses trabalhadores.

\section{Da proteção ao trabalho do menor de idade no meio rural}

Da proteção ao trabalho do menor de idade na CLT

O trabalho do menor de idade é tratado pela CLT, no Capítulo IV do Título III, mais especificamente nos artigos 402 a $441^{8}$ da citada Consolidação, contudo, é preciso ressaltar que a preocupação da CLT não é somente quanto ao menor de idade que trabalhe no meio rural. Devido a isso, como se exporá, as normas protetivas contidas na CLT regulam todo e qualquer trabalho do menor de idade.

Como exposto alhures, a CLT começa o capítulo referente à proteção do trabalho do menor de idade com a delimitação acerca da idade bem como em que idade o trabalhador poderá ser admitido e em que condição (aprendiz ou não). Estabelece ainda que o trabalho do menor de idade seja regulado pelo disposto nos artigos citados, exceto no serviço em oficinas em que trabalhem exclusivamente pessoas da família e desde que esteja sob a orientação do pai, mãe ou tutor, e que seja observado o disposto nos arts. 404405 e nos arts. 411 a 414, que adiante serão tratados.

\footnotetext{
${ }^{7}$ Súmula 331 do TST. Contrato de prestação de serviços. Legalidade. I, II, III... IV - 0 inadimplemento das obrigações trabalhistas, por parte do empregador, implica a responsabilidade subsidiária do tomador de serviços, quanto àquelas obrigações, inclusive quanto aos órgãos da administração direta, das autarquias, das fundações públicas, das empresas públicas e das sociedades de economia mista, desde que hajam participado da relação processual e constem também do título executivo judicial.

${ }^{8}$ Vade Mecum. Op. Cit. pp. 738 a 741.
} 
Ao menor de 18 (dezoito) anos é vedado o trabalho noturno, conforme estabelece 0 art. 404. Para efeitos de delimitação, o próprio artigo estabelece que se considere noturno 0 período compreendido entre 22 (vinte e duas) horas e 5 (cinco) horas. É importante salientar que para efeitos de trabalho rural, o trabalho do menor de idade é proibido entre os períodos compreendidos entre 21 (vinte e uma) e 5 (cinco) horas na lavoura, e na pecuária entre 20 (vinte) e 4 (quatro) horas (em decorrência da Lei 5.889/73).

0 art. 405 veda o trabalho: (a) em locais e serviços perigosos ou insalubres, constantes de quadro para esse fim; e (b) em locais ou serviços prejudiciais à sua moralidade.

O art. 193 da CLT estabelece que atividades ou serviços perigosos são aquelas que, por sua natureza ou métodos de trabalho, impliquem o contato permanente com inflamáveis ou explosivos em condições de risco acentuado. Contudo, maior regulamentação acerca do que sejam essas condições de periculosidade a lei deixou a cargo do M inistério do Trabalho. As atividades insalubres, por sua vez, estão dispostas no art. 183 do mesmo estatuto legal que assim considera aquelas atividades que, por sua natureza, condições ou métodos de trabalho, exponham os empregados a agentes nocivos à saúde, acima dos limites de tolerância fixados em razão da natureza e da intensidade do agente e do tempo de exposição aos seus efeitos. Contudo, a referida norma também deve ter regulamentação própria do M inistério do Trabalho quanto à delimitação dos agentes considerados nocivos à saúde.

Já 0 §50 do art. 405 remete ao artigo 390 e seu parágrafo único, que veda trabalho ou serviço que demande emprego de força muscular superior a 20 (vinte) quilos para 0 trabalho contínuo, ou 25 (vinte e cinco) para o trabalho ocasional. Essa limitação, contudo, não é aplicável no caso em que a remoção do peso seja efetuada com ajuda de impulsão ou por tração de vagonetes sobre trilhos, de carros de mão ou quaisquer aparelhos mecânicos, como estabelece o parágrafo primeiro.

Se a autoridade competente verificar que 0 trabalho exercido pelo menor de idade seja prejudicial à sua saúde, ao seu desenvolvimento físico ou à sua moralidade, essa autoridade poderá obrigá-lo a abandonar o serviço, devendo a empresa, se for o caso, dar todas as condições para que isso aconteça (art. 407). Caso a empresa não tome as devidas 
providências, poderá ser caracterizada a rescisão indireta do contrato de trabalho, nos termos do art. 483.

0 responsável legal do menor de idade trabalhador também pode pleitear a extinção do contrato de trabalho se verificar que possa ocorrer algum prejuízo de ordem física ou moral (art. 408).

O legislador dá a faculdade ao fiscalizador de proibir que o menor de idade tenha seus períodos de repouso nos locais de trabalho, com escopo de garantir a integridade de sua saúde.

Desaparecendo o caráter perigoso ou insalubre do local de trabalho do menor, o Ministério do Trabalho poderá derrogar a proibição quanto ao trabalho do menor de 18 (dezoito) anos (art. 410).

A duração do trabalho do menor de idade é a mesma que seria realizada pelo adulto, conforme estabelece 0 art. 411. Contudo, os artigos seguintes enumeram as restrições que deverão ser observadas.

0 intervalo para repouso entre cada período de trabalho, quer seja dividido em dois turnos ou um turno seguidamente, nunca poderá ser inferior à 11 (onze) horas, como reza o art. 412.

Ao menor de idade é proibida a prorrogação da duração do trabalho normal, exceto: (a) até mais 2 (duas) horas, independentemente de acréscimo salarial, mediante convenção ou acordo coletivo nos termos do Título VI da CLT, e desde que o excesso de horas em um dia seja compensado pela diminuição em outro, com o limite máximo de 48 (quarenta e oito) horas semanais, ou outro inferior se a lei assim estabelecer; (b) e, excepcionalmente, por motivo de força maior, até o máximo de 12 (doze) horas, com acréscimo salarial de no mínimo 25\% (vinte e cinco por cento) sobre a hora normal, se 0 trabalho do menor de idade for imprescindível ao estabelecimento (art. 413). Todavia, de acordo com 0 art. 7ํ, XVI da Constituição, o percentual sobre a hora normal é de no mínimo $50 \%$ (cinqüenta por cento). Ou seja, respeitando as peculiaridades do trabalho do menor de idade, deve-se entender que além do estabelecido pela própria Constituição, seja acrescentado $25 \%$, resultando um acréscimo de $75 \%$ (setenta e cinco por cento) sobre a hora normal, caso haja necessidade de jornada extra de trabalho. Salienta-se que antes do 
período de trabalho prorrogado deverá haver um intervalo de descanso de no mínimo 15 (quinze) minutos (parágrafo único do art. $413 \mathrm{c} / \mathrm{c}$ art. 384).

Se o menor de idade for empregado em mais de um estabelecimento, as horas de trabalho serão totalizadas para os efeitos do disposto quanto ao período de trabalho (art. 414).

Quanto às penalidades, a CLT prevê multa do valor igual a um salário mínimo, aplicada tantas vezes quantos forem os menores de idade empregados em desacordo com a lei, todavia, não podendo essa multa ultrapassar o valor de cinco vezes o salário mínimo, exceto no caso de reincidência, em que o total será elevado ao dobro (art. 434). Em caso de anotação não prevista em lei na carteira de trabalho do menor de idade, o empregador fica sujeito à multa de um salário mínimo mais as custas para emissão de uma nova Carteira de Trabalho (art. 435).

São competentes para impor as referidas sanções os Delegados Regionais do Trabalho ou os funcionários designados para esse fim. 0 processo referente à cobrança das multas está disciplinado em título próprio (art. 438 e seu parágrafo único).

Por fim, ressalta-se que todas essas regras, observados as características peculiares do trabalho rural, são aplicáveis ao menor de idade que labora nesse meio.

0 menor de idade trabalhador na agricultura familiar

A Agricultura Familiar é regulamentada pela Lei 11.326 de 24 de julho de 2006. Essa lei estabelece as diretrizes para a formulação da Política Nacional da Agricultura Familiar e Empreendimentos Familiares Rurais.

Conforme estabelece 0 art. $3^{\circ}$ da lei ora em comento:

Para os efeitos desta Lei, considera-se agricultor familiar e empreendedor familiar rural aquele que pratica atividades no meio rural, atendendo, simultaneamente, aos seguintes requisitos: I - não detenha, a qualquer título, área maior do que 4 (quatro) módulos fiscais; II - utilize predominantemente mão-de-obra da própria família nas atividades econômicas do seu estabelecimento ou empreendimento; III - tenha renda familiar predominantemente originada de atividades econômicas vinculadas ao próprio estabelecimento ou empreendimento; IV - dirija seu estabelecimento ou empreendimento com sua família.

0 § do mesmo artigo, continua dizendo que

São também beneficiários desta Lei: I - silvicultores que atendam simultaneamente a todos os requisitos do caput deste artigo, cultivem florestas nativas ou exóticas e que promovam o manejo sustentável daqueles ambientes; II - aqüicultores que 
atendam simultaneamente a todos os requisitos de que trata o caput deste artigo e explorem reservatórios hídricos com superfície total de até 2 há (dois hectares) ou ocupem até $500 \mathrm{~m} 3$ (quinhentos metros cúbicos) de água, quando a exploração se efetivar em tanques-rede; III - extrativistas que atendam simultaneamente aos requisitos previstos nos incisos II, III e IV do caput deste artigo e exerçam essa atividade artesanalmente no meio rural, excluídos garimpeiros e faiscadores; IV pescadores que atendam simultaneamente os requisitos previstos nos incisos I, II, III e IV do caput deste artigo e exerçam a atividade pesqueira artesanalmente.

Diante do exposto, verificada as condições específicas da agricultura familiar exigidas pela lei, ao menor de idade é permitido o trabalho nesse contexto, desde que, obedecidas as regras proibitivas quanto ao trabalho noturno, perigoso ou insalubre, observados também os horários de trabalho desse menor, conforme o disposto nos arts. 411 a 414 da CLT, bem como esse menor de idade tenha freqüência obrigatória na escola, tudo em conseqüência do princípio da proteção integral. É o que dispõe o parágrafo único do art. 402 da CLT e o caput do art. 67 do ECA, sendo que no trabalho realizado pelo menor de idade na agricultura familiar ele deve estar sob a direção do pai, mãe ou tutor.

A proteção ao trabalho do menor de idade no ECA

O ECA trata do Direito à Profissionalização e da Proteção do Trabalho do menor de idade nos artigos 60 a 69, mais especificamente no seu Título II, Capítulo V.

0 próprio Estatuto, no seu art. 61 remete a regulamento próprio quanto à proteção do trabalho do menor de idade, contudo, sem prejuízo do disposto do que nele está disposto. 0 regulamento próprio é a CLT, que já foi objeto de estudo.

$\mathrm{Na}$ realidade, o que se pode observar do próprio Estatuto que ele lança as bases da proteção ao trabalho do menor de idade, fazendo-o em consonância com o princípio da proteção integral positivado na Constituição, deixando para que a legislação própria trate dos temas mais específicos, como faz a CLT.

Nesse diapasão, 0 Estatuto no art. 62 em consonância com 0 art. 428 da norma celetista, reza que se considera aprendizagem a formação técnico-profissional ministrada segundo as diretrizes e bases da legislação de educação em vigência. Oris de Oliveira (CURY 2005, p. 214) comentando o citado artigo diz que

na visão ampla do art. 62 do ECA não há dicotomia entre aprendizagem e educação. Pelo contrário, inserindo-se no processo educacional na educação 
permanente, continuada, ela é uma das primeiras etapas de um processo que deve perdurar e sempre aperfeiçoar-se durante toda a vida do cidadão.

Continuando o tema, 0 art. 63 estabelece que essa formação deve obedecer a três princípios, sendo: (a) o da garantia de acesso e freqüência obrigatória ao ensino regular; (b) o do exercício de atividade compatível com o desenvolvimento do adolescente; e (c) horário especial para o exercício das atividades.

Esses princípios positivados no Estatuto harmonizam-se com o Princípio da Proteção Integral posto art. 227 da Carta Maior. A garantia do acesso e freqüência obrigatória ao ensino regular encontra respaldo também no §3ㅇ, III do mesmo artigo da Constituição Federal. 0 princípio garante que 0 menor de idade não fique restrito ao ensino profissionalizante de aprendizagem, ou seja, o ensino regular deve ser freqüentado, e como já exposto, essa freqüência é obrigatória. Com relação ao trabalho do menor de idade no meio rural, a Lei 5.889/73 também se preocupa com o tema, quando estabelece que em propriedades rurais onde haja mais de 50 (cinqüenta) famílias, deverá haver uma escola primária. Com o advento das novas diretrizes e bases da educação nacional, ao invés de escola primária, leia-se escola de ensino fundamental.

A leitura desse princípio remete ao Capítulo IV também do Título II do ECA, onde o art. 53 garante o direito da criança e do adolescente à educação, e nos termos da lei, preparando-o para o exercício da cidadania e qualificando-o para o trabalho, artigos estes que estão em perfeita consonância com o disposto nos arts. 205 e 206 da Constituição Federal.

0 segundo princípio posto no art. 63 é o que o exercício da atividade do adolescente deve ser compatível com a sua condição, em harmonia com o inciso I do art. 69, que, em suma, estabelece que esse direito a profissionalização deve respeitar à condição peculiar de pessoa em desenvolvimento.

Todavia, não é essa a realidade que se encontra no trabalho do menor de idade no Brasil, principalmente no meio rural, como se comprovará pelos dados apresentados e pela pesquisa realizada. 0 trabalho do menor de idade no meio rural, antes dos 16 (dezesseis) anos deveria ser realizado somente por aprendizagem, por meio de escolas agrícolas, por exemplo. E mesmo após os dezesseis anos o trabalho deveria obedecer às regras celetistas já mencionadas, e ao disposto nos incisos do art. 67 do próprio ECA, mais especificamente 0 
inciso III. Admite-se como socialmente prejudicial todo trabalho que concretamente priva o adolescente do convívio com a família, com a escola, com o lazer, com atividades sociais (CURY, 2005 p. 233).

E no terceiro princípio é preciso entender que o menor de idade aprendiz deva ter horários específicos para o estudo regular, bem como, a convivência familiar e social, contemplada pelo próprio Estatuto nos arts. 19 e seguintes.

0 artigo 64 do Estatuto na realidade não pode ser interpretado literalmente. Estabelece que "ao adolescente até 14 (quatorze) anos de idade é assegurada bolsa de aprendizagem", e, como já exposto, aos menores dessa idade é proibido qualquer tipo de trabalho, inclusive na condição de aprendiz. Entretanto, uma interpretação teleológica do artigo, garante que a remuneração dos aprendizes, nos termos do $2^{\circ}$ do art. 428 da CLT, seja o salário mínimo hora.

0 art. 65 garante, como 0 §1ㅇ do art. 428 da CLT, anotação em Carteira de Trabalho e Previdência Social, assegurando ao menor de idade trabalhador todos os direitos decorrentes da relação de trabalho, inclusive para fins previdenciários.

0 art. 66 dá proteção ao trabalho do adolescente portador de deficiência, não sendo aplicável a idade máxima de 24 (vinte e quatro) anos para a contratação por meio de contrato de aprendizagem ( $\$ 50$ do art. 428 da CLT).

0 art. 67 juntamente com todo o disposto na CLT e já comentado, proíbe o trabalho noturno, insalubre, perigoso e penoso; àqueles realizados em locais prejudiciais à sua formação e ao seu desenvolvimento físico, psíquico, moral e social; bem como àqueles trabalhos que não permitam a freqüência escolar. Esse artigo é na realidade a base das regras a serem seguidas por quem emprega um menor de idade.

Com relação ao programa de aprendizagem ou social que tenha por base 0 trabalho educativo, governamental ou não, deve assegurar ao adolescente sua participação das condições de capacitação para o exercício de atividade regular remunerada. 0 disposto no art. 68, caput, quer garantir formação ao adolescente que trabalhe com finalidade educativa, para o mercado de trabalho. É na realidade também a base do trabalho na condição de aprendiz. Para melhor entender o que vem a ser o trabalho educativo, 0 \$1 0 do citado artigo reza que esse trabalho é aquele em que as exigências pedagógicas relativas ao desenvolvimento social do educando prevalecem sobre o aspecto produtivo. Quer dizer, não 
existe uma preocupação econômica no trabalho realizado pelo menor de idade. Contudo, observando 0 §2으, mesmo que 0 adolescente participe financeiramente das vendas de seu trabalho, não há descaracterização da finalidade educativa.

Ao adolescente trabalhador é garantido 0 direito à profissionalização e a proteção ao seu trabalho, sendo que, deverá haver respeito à sua condição peculiar de pessoa em desenvolvimento, bem como seu trabalho o capacite profissionalmente de maneira adequada ao mercado de trabalho (art. 69).

\section{A aplicabilidade das normas referentes ao trabalho do menor de idade no meio rural contidas na constituição federal, na CLT e no ECA}

Ao menor de idade trabalhador no meio rural são garantidos todos os direitos postos na Constituição, na CLT e no ECA.

Observada a peculiaridade do trabalho rural, o princípio da proteção integral posto no art. 227 da Carta Magna é aplicável, principalmente no que tange a idade mínima de 16 (dezesseis) anos, e a partir dos 14 (quatorze) como aprendiz. Essa garantia remete aos direitos trabalhistas e previdenciários que também são assegurados, concomitantemente à obrigação de freqüência do menor de idade trabalhador na escola.

A proibição contida tanto na CLT quanto no ECA quanto ao trabalho noturno, perigo, penoso e insalubre também se estende ao meio rural.

As regras referentes aos horários do trabalho do menor de idade deverão ser observadas, principalmente no que diz respeito a proibição de intervalo de repouso inferior a 11 (onze) horas entre uma jornada e outra, e a vedação da prorrogação da duração normal diária do trabalho, exceto quando observado o disposto nos incisos I e II do art. 413 da CLT, como já exposto. Se o menor de idade for empregado em mais de uma propriedade rural, as horas devem ser totalizadas para efeitos de jornada de trabalho (art. 414 da CLT).

Os maiores de 14 (quatorze) anos poderão ser contratados como aprendizes no meio rural, desde que se respeite toda a legislação pertinente, bem como exista 0 intermédio de entidade de formação específica, no caso, escolas agrícolas, por exemplo. É importante salientar que também os estabelecimentos do meio rural estão obrigados a empregar e matricular nos cursos de aprendizagem no mínimo 5\% (cinco por cento) e no máximo 15\% (quinze por cento) dos trabalhadores existentes. Se contratado na forma de 
aprendizado, o trabalho não poderá exceder a 6 (seis) horas diárias, chegando ao limite de 8 (oito) horas se 0 aprendiz já tiver completado o ensino fundamental e nelas forem computadas as horas destinadas à aprendizagem teórica.

É garantido ao menor de idade trabalhador no meio rural salário mínimo hora, ou outra condição mais favorável.

Com relação ao trabalho na propriedade familiar agrícola, aplica-se a proibição quanto ao trabalho noturno, perigoso, insalubres e penosos (art. 404 e 405), bem como as regras referentes à duração do trabalho.

As diretrizes postas no ECA deverão ser observadas quanto ao trabalho do menor de idade no meio rural, seja ou não na condição de aprendiz.

\section{Conclusão}

A Constituição de 1988 é expressa quanto ao Princípio da Proteção Integral do menor de idade, garantido-Ihes todos os direitos de cidadão, e que devem ser conferidos mediante ação prioritária do Estado. Diante disso, e por legislação infraconstitucional, no caso o ECA, criou-se órgãos de proteção à criança e ao adolescente, como o Conselho Tutelar, que tem autonomia para aplicar medidas protetivas sem a intervenção do Poder Judiciário, legitimando também a responsabilidade de toda sociedade, por se tratar de direito difuso (criança e adolescente).

A Constituição também equiparou os trabalhadores urbanos e rurais em direitos, tendo esse último tipo de trabalho regulamentação específica na Lei 5.889/73, sem, contudo, atentar-se de maneira específica ao trabalho do menor de idade no meio rural, deixando isso a cargo da CLT e do ECA, não observando as peculiaridades desse tipo de trabalho.

Diante da legislação pertinente, se aplica ao trabalho rural do menor de idade 0 disposto também na CLT e no ECA, que, diante do princípio da proteção integral, proíbe qualquer trabalho aos menores de 16 (dezesseis) anos, exceto na condição de aprendiz, a partir dos 14 (quatorze). Proíbe também o trabalho em condições insalubres, perigosas, noturnas e penosas aos menores de 18 (dezoito) anos, autorizando, entretanto, a contratação desses jovens como aprendizes rurais, respeitando os limites mencionados. 
No meio rural, como no urbano, é obrigatório a contratação de no mínimo 5\% (cinco por cento) e no máximo 15\% (quinze por cento) de aprendizes, por meio de entidades sem fins lucrativos devidamente registradas no Conselho Municipal da Criança e do Adolescente, ou de Escolas Agrícolas devidamente autorizadas pelo Ministério da Educação, por exemplo, implantando programas de aprendizagem para adolescentes e adultos, considerando que o contrato de aprendizagem pode ser celebrado até os 24 (vinte e quatro) anos.

Portanto, o trabalho desprotegido não pode ser considerado uma alternativa aos menores de idade que são marginalizados no campo, sendo que o referido problema deve ser enfrentado pelo Estado, mediante políticas públicas de proteção, bem como de toda a sociedade, organizada ou não, por se tratar de direito difuso, logo, de responsabilidade de todos.

\section{Referências}

AM ARAL, Vilma Aparecida do et al. Comentários à consolidação das Leis do Trabalho. 26. ed. Atualizada por Eduardo Carrion. São Paulo: Saraiva, 2001.

CURY, M unir. Estatuto da Criança e do Adolescente comentado: comentários jurídicos e sociais. São Paulo: Malheiros, 2005.

DELGADO, Mauricio Godinho. Curso de direito do trabalho. 4. ed. São Paulo: LTr, 2005.

GIORDANI, Francisco Alberto da Motta Peixoto; M ARTINS, M elchíades Rodrigues; HINIZ, Henrique Macedo. Direito individual do trabalho. São Paulo: Saraiva, 2006.

M ANUS, Pedro Paulo Teixeira. Direito do trabalho. 7. ed. São Paulo: Atlas, 2002.

M ARTINS, Sergio Pinto. Direito do trabalho. 2. ed. São Paulo: Editora Atlas, 2006.

NASCIM ENTO, Amauri M ascaro. Iniciação ao direito do trabalho. 32. ed. São Paulo: LTr, 2006.

PELEGRINO, Antenor. Trabalho rural. 8. ed. São Paulo: Editora Atlas, 1999.

REALE, M iguel. Lições preliminares de direito. 27. ed. São Paulo: Saraiva, 2002.

ROCHA, Eduardo Gonçalves; PEREIRA, Juliana Faria. Descentralização Participativa e a Doutrina da Proteção Integral da Criança e do Adolescente. Disponível em: 
«ttp://www.proec.ufg.br/revista_ufg/infancia/P_descentraliza.html>. Acesso em: 26 jan. 2007.

SANTORO, Vivien S.; STEVANATO, Naíra Junqueira. Eca nas escolas. Revista Estação, Londrina, v. 6, n. 4, dez. 2005. Disponível em:

«ttp://www.proex.uel.br/estacao/index.php?arq=ARQ_art\&FWS_Ano_Edicao $=3 \& F W S_{-} N_{-} E$ dicao $=4 \& F W S_{-}$Cod_Categoria $=1 \& F W S_{-} N_{-}$Texto $=2>$.

SEGUNDO, Rinaldo. Notas sobre o direito da criança . Jus Navigandi, Teresina, v. 7, n. 61, jan. 2003. Disponível em: «tttp://jus2.uol.com.br/doutrina/texto.asp?id=3626>. Acesso em: 27 jan. 2007.

SILVA, José Afonso da. Curso de direito constitucional positivo. 23. ed. São Paulo: Malheiros, 2004.

SILVA, Luiz de Pinho Pedreira da. Principiologia do direito do trabalho. São Paulo: Editora LTr, 1999.

SÜSSEKIND, Arnaldo et al. Instituições de direito do trabalho. 21. ed. São Paulo: LTr, 2003.

TEIXEIRA, Wendel de Brito Lemos. A discrepância entre a idade mínima laboral e a realidade brasileira . Jus Navigandi, Teresina, v. 7, n. 62, fev. 2003. Disponível em:

ঝttp://jus2.uol.com.br/doutrina/texto.asp?id=3710>. Acesso em: 15 jun. 2006.

VIDOTTI, Tarcio José. Direito do trabalho rural. 2. ed. São Paulo: Editora LTr. 2005 